\title{
МОНИТОРИНГ ТЕХНИЧЕСКОГО СОСТОЯНИЯ ЗДАНИЙ И СООРУЖЕНИЙ
}

\author{
Виктория Анатольевна Дементьева \\ Сибирский государственный университет геосистем и технологий, 630108, Россия, \\ г. Новосибирск, ул. Плахотного, 10, обучающийся, тел. (383)361-01-09, e-mail: d-v-a@bk.ru
}

\section{Алина Ивановна Радионова}

Сибирский государственный университет геосистем и технологий, 630108, Россия, г. Новосибирск, ул. Плахотного, 10, обучающийся, тел. (383)361-01-09, e-mail: alina100699@mail.ru

Мониторинг - это организационное систематизированное наблюдение, которое проводится для контроля и прогнозирования технического состояния зданий и сооружений, а также своевременного выявления тенденций негативных изменений. С каждым годом растет количество объектов недвижимости, что ведет к росту потребности проведения мониторинга зданий и сооружений на предмет физического и морального износа, реконструкций, изменений форм собственности и повышений цен на недвижимое имущество. Мониторинг зданий и сооружений очень важен при изменении конструктивных схем и при необходимости учета современных норм проектирований зданий. Здание, которое находится в процессе эксплуатации может подвергаться физическому износу строительных конструкций. Это снижение и потеря несущих способностей, деформация отдельных элементов, а также здания в целом. Восстановление эксплуатационных качеств конструкции невозможно без мониторинга, при котором выявляются причины преждевременного износа зданий и сооружений.

Ключевые слова: мониторинг, здания, сооружения, наблюдение, контроль, техническое состояние, обследование

\section{MONITORING OF THE TECHNICAL CONDITION OF BUILDINGS AND STRUCTURES}

\section{Victoria A. Dementyeva}

Siberian State University of Geosystems and Technologies, 10, Plakhotnogo St., Novosibirsk, 630108, Russia, Student, phone: (383)361-01-09, e-mail: d-v-a@bk.ru

\section{Alina I. Radionova}

Siberian State University of Geosystems and Technologies, 10, Plakhotnogo St., Novosibirsk, 630108, Russia, Student, phone: (383)361-01-09, e-mail: alina100699@mail.ru

Monitoring is an organizational systematic observation is carried out to monitor and predict the technical condition of buildings and structures, as well as timely identify trends of negative changes. The number of real estate objects is growing every year, which leads to an increase in the volume of monitoring of buildings and structures due to physical and moral deterioration, reconstruction, changes in forms of ownership and increases in real estate prices. Monitoring of buildings and structures is very important when changing design schemes and when it is necessary to take into account modern building design standards. A building that is in operation may be a subject to physical wear and tear of building structures. This reduction and loss of load-bearing capacity, deformation of individual elements, as well as the building as a whole. It is impossible to restore the operational qualities of the structure without monitoring, which identifies the causes of premature wear of buildings and structures.

Keywords: monitoring, buildings, structures, observation, control, technical condition, survey 
В последнее время в России строится большое количество уникальных зданий и сооружений, которые отличаются интересными конструктивными решениями, строятся из новых материалов и с помощью новых технологий возведения. Под такими зданиями и сооружениями подразумеваются: мосты, туннели, высотные жилые здания, памятники архитектуры и так далее. Но, к сожалению, очень часто строительство таких зданий и сооружений отличается еще и неквалифицированными проектировщиками, строителями и монтажниками. Из-за этого уже после нескольких лет эксплуатации состояние здания начинает ухудшаться и иметь небезопасный характер. Это приводит к необходимости проведения мониторинга технического состояния данных объектов. На рис. 1 приведены основные цели проведения мониторинга технического состояния.

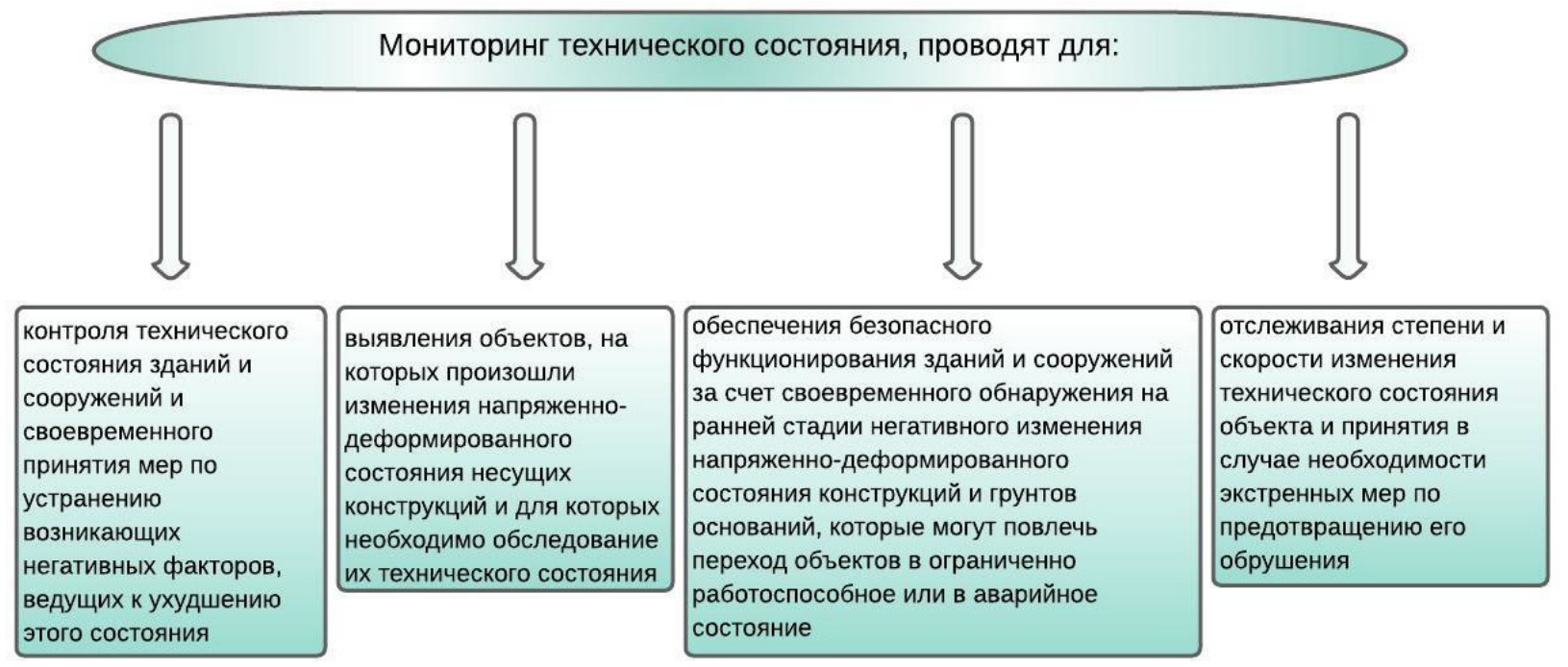

Рис. 1. Цели проведения мониторинга технического состояния

Мониторинг - (в широком смысле, от лат. Monitor - предостерегающий) специально организованное, систематическое наблюдение за состоянием объектов, явлений, процессов с целью их оценки, контроля или прогноза. На рис. 2 показана система мониторинга [1].

Из данного рисунка можно сделать вывод, что мониторинг - это процесс наблюдения и контроля, которые проводятся на постоянной основе и по определенной системе, служащий для оценки состояния зданий и сооружений, а также происходящих процессов и своевременного выявления причин негативного изменения во всей конструкции, инженерной сети и ее отдельных узлов. В настоящее время мониторинг и обследование зданий регламентируется согласно СП 13 102-2003 «Правила обследования несущих строительных конструкций зданий и сооружений», принятые и рекомендованные к применению в качестве нормативного документа в системе нормативных документов в строительстве постановлением Госстроя России от 21 августа 2003 года №153. 


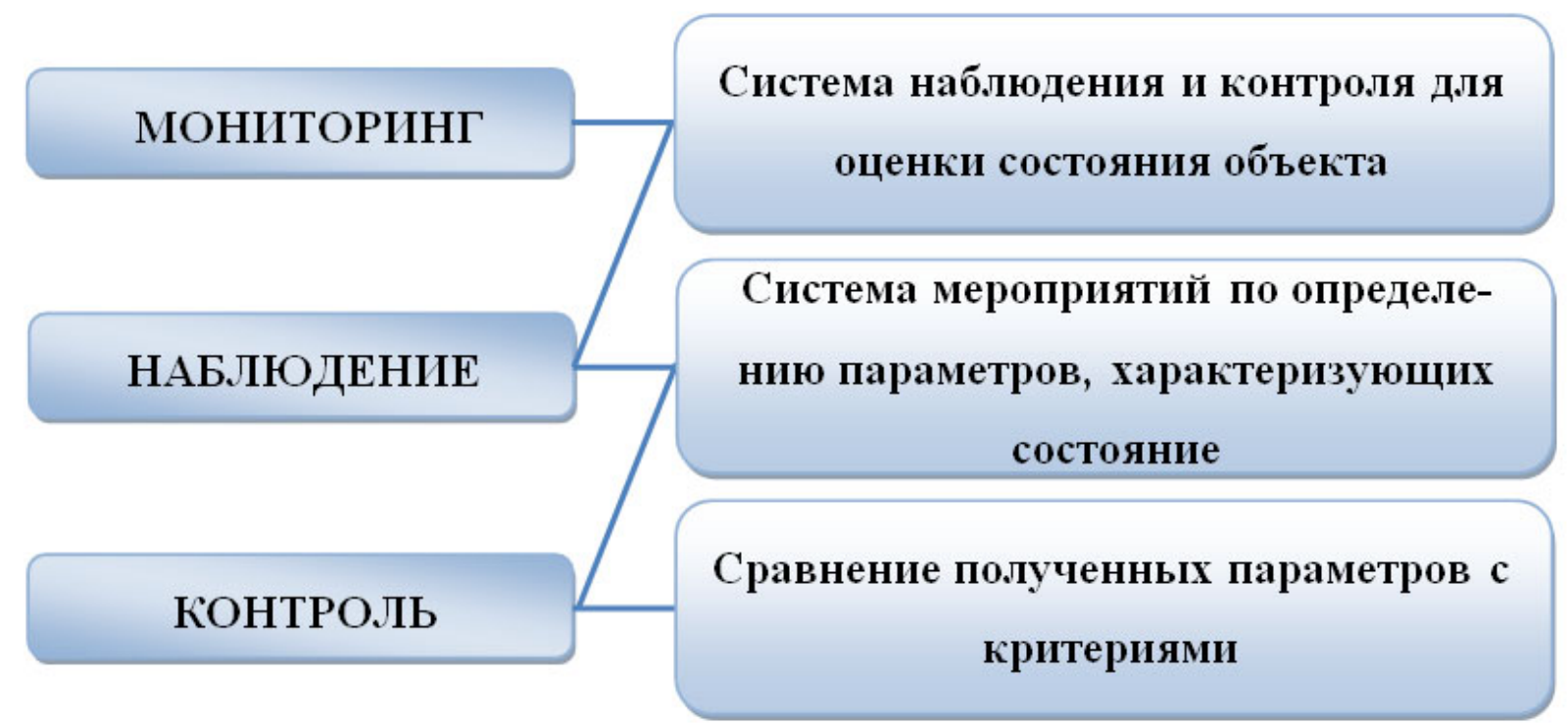

Рис. 2. Система мониторинга

Мониторинг технического состояния состоит из 4 этапов, показанных на рис. 3.

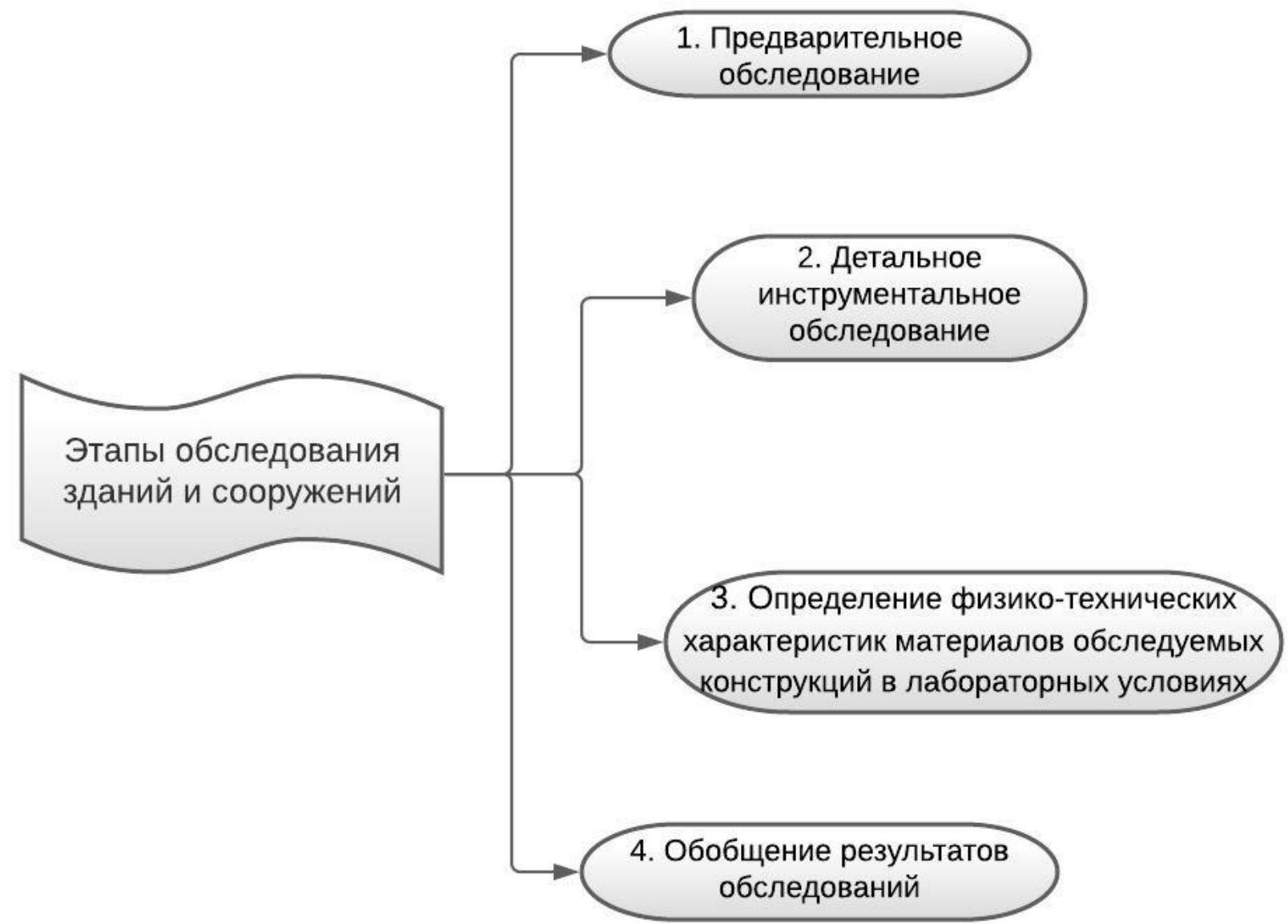

Рис. 3. Этапы проведения мониторинга 
Первое обследование технического состояния здания или сооружения происходит максимум через два года после ввода его в эксплуатацию. Далее, уже одного раза в 10 лет достаточно. Но если здание или сооружение находится в неблагоприятной зоне, то мониторинг проводят один раз в пять лет [2].

Повторное обследование зданий и их элементов, находящихся в аварийном состоянии, - раз в шесть месяцев, находящихся в ветхом состоянии - раз в год, в неудовлетворительном состоянии - раз в два года, а также выборочное обследование отдельных конструкций и систем по запросам владельцев при выходе их из строя, повреждениях, нарушениях режимов с ежегодным анализом всех заявок, поступивших в объединенные диспетчерские системы (ОДС), для планирования текущего ремонта и технического обслуживания (ТО).

Данный мониторинг должны проводить специализированные организации, которые имеют современные приборы и высококвалифицированных специалистов. Требования к данным организациям определяются федеральным органом исполнительной власти, уполномоченным на ведение государственного строительного надзора. Федеральным органом исполнительной власти, уполномоченным на ведение государственного строительного надзора, также ведется реестр специализированных организаций. На рис. 4 представлены обследование и оценка технического состояния.

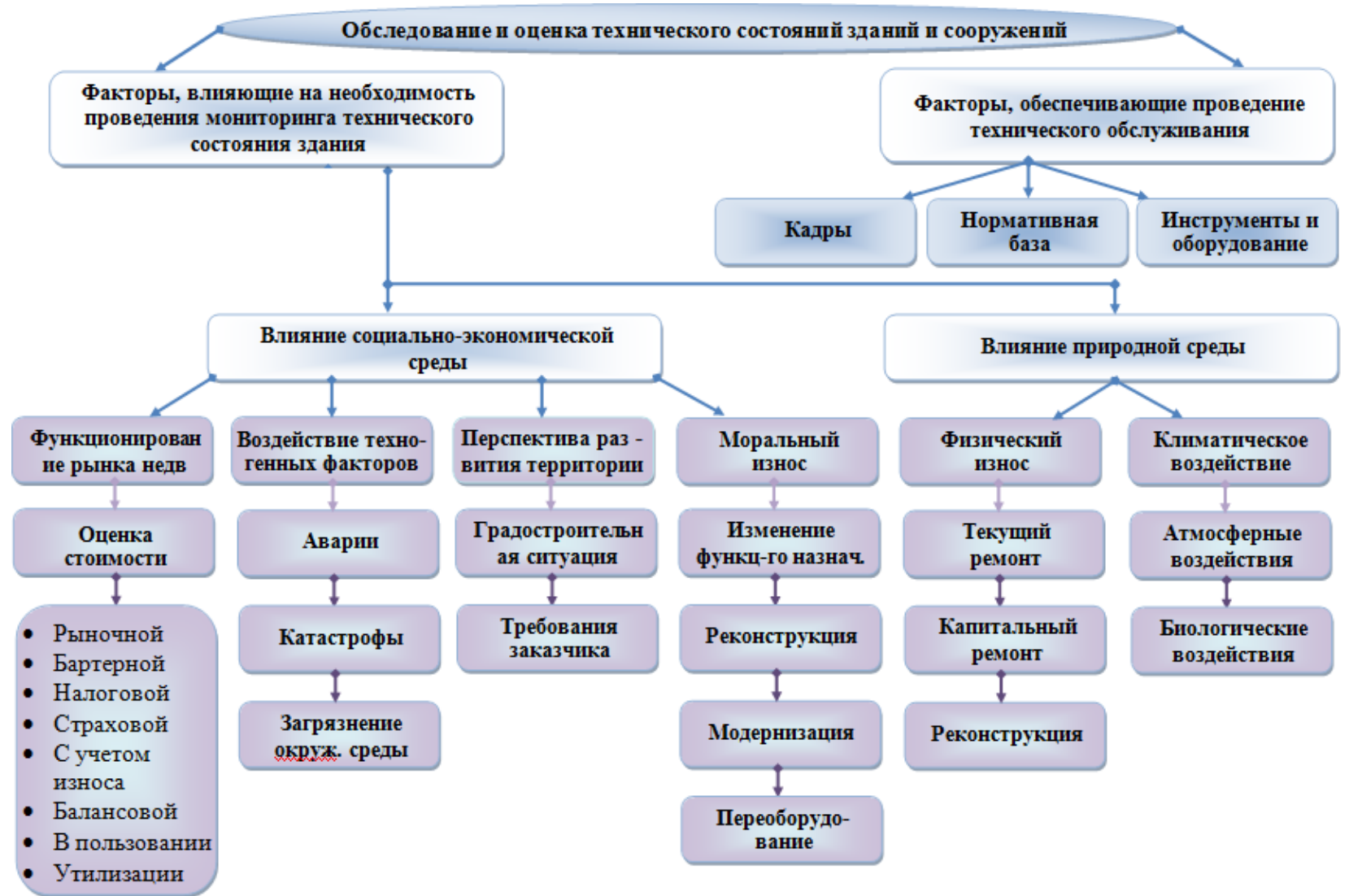

Рис. 4. Обследование и оценка технического состояний зданий и сооружений 
Также причинами проведения мониторинга могут являться последствия пожара, аварий, стихийных бедствий, значительные дефекты, а также по инициативе собственника и по предписанию органов, которые уполномочены на ведение государственного строительного надзора [3].

Выбор системы наблюдения зависит от цели проведения мониторинга. Программу мониторинга обязательно согласовывают с заказчиком. В данной программе должны содержаться используемые виды работ, периодичность наблюдений с учетом технического состояния объекта и общей продолжительности мониторинга. Методика и объем системы наблюдений при мониторинге, включая измерения, должны обеспечивать достоверность и полноту получаемой информации для подготовки исполнителем обоснованного заключения о текущем техническом состоянии объекта (объектов).

Перед проведением мониторинга просматривают архивные материалы, которые содержат информацию о техническом состоянии объекта. После выдается задание на обследование каждого объекта, где учитываются его особенности и слабые элементы. Осматривают все его части от кровли и фасада до подвалов, чердаков, лестничных клеток и т.д. В каждом помещении осматриваются все конструкции и инженерное оборудование. Все дефекты заносятся в рабочий журнал. Если невозможно определить причины деформаций визуально, то проводится дополнительное инструментальное обследование, уделяя особое внимание аварийным участкам и узлам. В процессе мониторинга прописываются рекомендации на необходимые срочные ремонтные и восстановительные работы.

После проверки вся информация классифицируется по видам конструкций и систем.

Дефекты и повреждения описываются по методике определения физического износа жилых зданий (ВСН-53-86 (p), где подробно описываются возможные дефекты и повреждения конструкций и элементов с указанием минимального объема контроля.

Оценка технического состояния здания представлена на рис. 5.

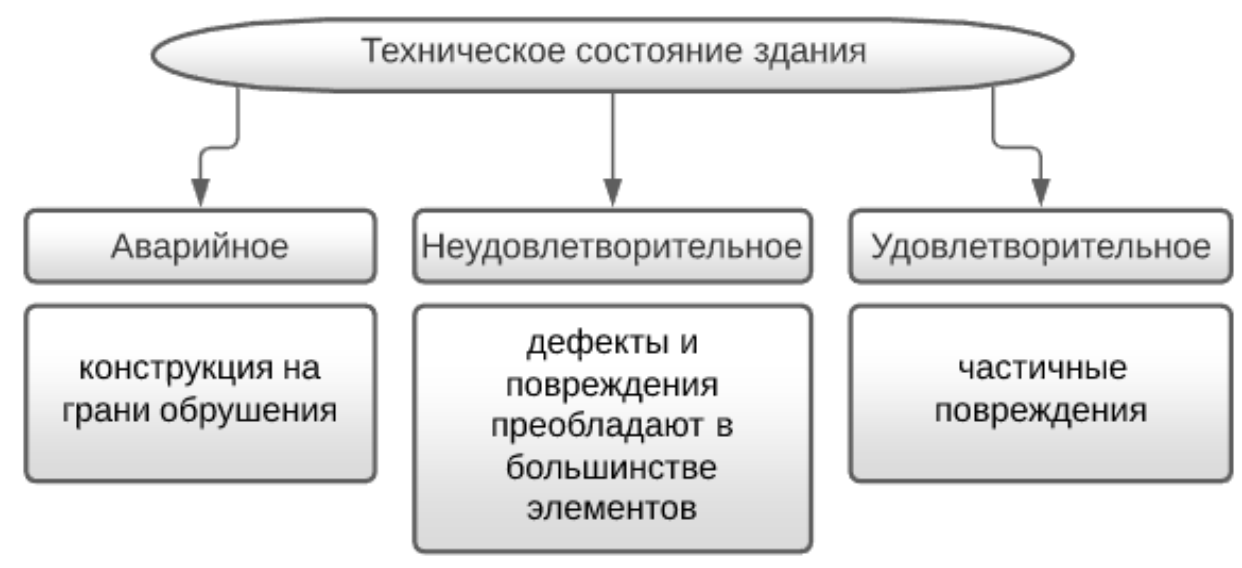

Рис. 5. Техническое состояние здания 
Заключением технического состояния жилого объекта являются документы, которые показаны на рис. 6.

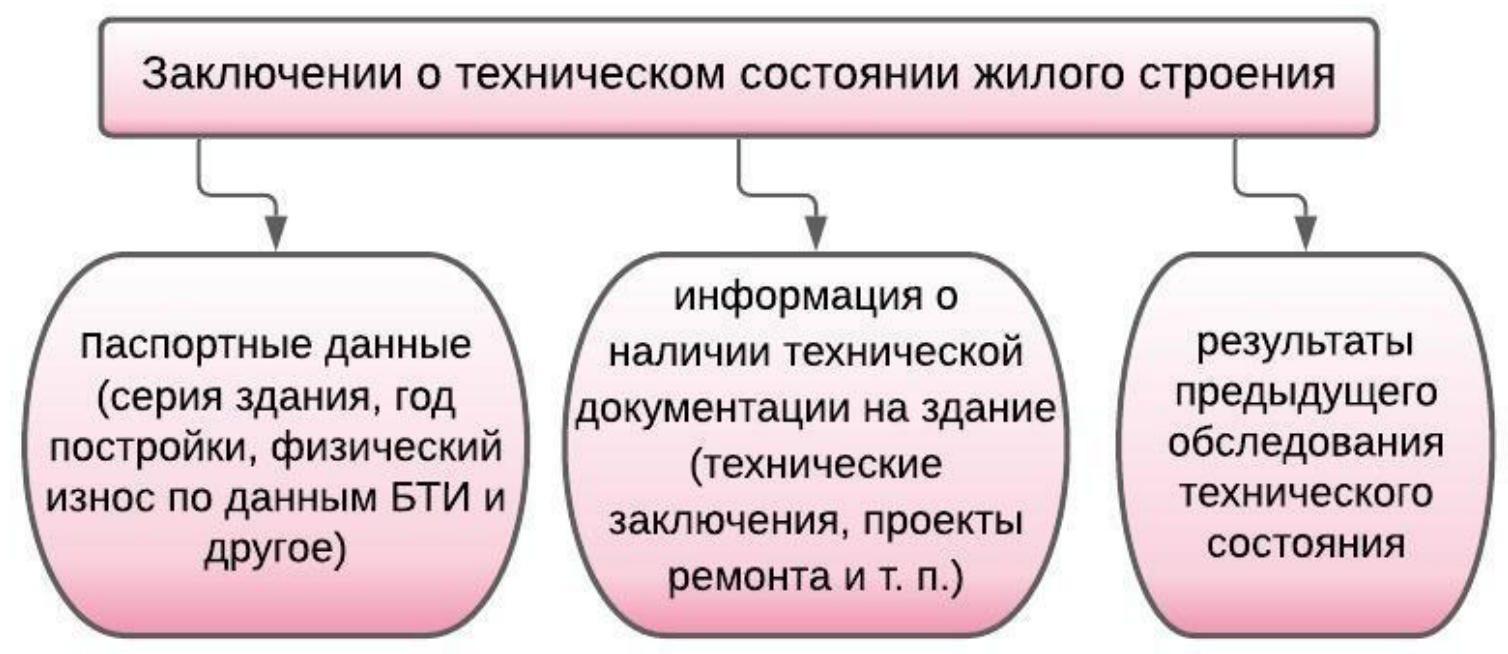

Рис. 6. Заключение о техническом состоянии

Результаты такого мониторинга используются для обеспечения безаварийного содержания жилых зданий, предупреждения появления таких аварий, а также формирования списков на капитальный ремонт объектов или отдельных его конструкций [4].

Последствиями плохого состояния зданий и сооружений является массовая гибель людей, так в 2015 году в Омске обрушились пролеты казармы учебного центра ВДВ и погибло 66 человек. И таких случаев достаточное количество. Основными причинами этих аварий являются ошибки, допущенные при проектировании, строительстве, эксплуатации объектов. А именно: отсутствие плана эвакуации в здании, отсутствие лица, отвечающего за состояние объекта, эксплуатация объектов в аварийном состоянии и многие другие.

При эксплуатации зданий и сооружений по причинам, описанным выше, происходит физический износ строительных конструкций, уменьшение их несущей способности, их деформация. Поэтому для устранения данных негативных изменений заранее и необходим мониторинг технического состояния.

Частая необходимость проведения мониторинга зданий и сооружений связана также с ошибками при их проектировании, строительстве и эксплуатации. Например, некачественные строительно-монтажные работы, использование бракованных опорных частей, недостаточно квалифицированные рабочие. Решением данных проблем является проведение работ с соблюдением всех требований нормативных документов [5]. 


\section{БИБЛИОГРАФИЧЕСКИЙ СПИСОК}

1. Бойко М.Д. Техническое обслуживание и ремонт зданий и сооружений. издат, 1986г.

2. Козачек В.Г., Нечаев Н.В., и др. Обследование и испытание зданий и сооружений. ФГУТТ «Издательство «Высшая школа», М., 2004г., 446с.

3. Национальный стандарт РФ ГОСТ Р 53778-2010 "Здания и сооружения. Правила обследования и мониторинга технического состояния" (утв. приказом Федерального агентства по техническому регулированию и метрологии от 25 марта 2010 г. N 37-ст). Москва, Стандартинформ ,2010.

4. Стражников А.М., Ройтман А.Г., Мониторинг технического состояния жилых зданий. Опыт городов и регионов. Москва. 2000г.,9с.

5. Обследование зданий и сооружений: проблемы и пути их решения: Материалы VIII международной научно-практической конференции. 13 октября 2017 года. - СПб. Изд-во Политехн. ун-та, 2017. - 248 с.

(C) В. А. Дементьева, А. И. Радионова, 2021 